\title{
LA DIPUTACIÓN PERMANENTE EN LA CONSTITUCIÓN DE CÁDIZ O EL INTENTO FRUSTRADO DE CREAR UN ÓRGANO CON FUNCIONES DE GARANTÍA CONSTITUCIONAL
}

ÁNGEL LUIS ALONSO DE ANTONIO 


\section{SUMARIO}

1. INTRODUCCIÓN. 2. DENOMINACIÓN. 3. CONSTITUCIONALIZACIÓN DEL ÓRGANO. SU JUSTIFICACIÓN. 4. CARACTERIZACIÓN DUAL DE SU NATURALEZA. A) Naturaleza jurídica. B) Naturaleza política. 5. CARACTERÍSTICAS. A) Carácter histórico. B) Sentido progresista C) Espíritu de control. 6. SU COMETIDO. FUNCIONES CONSTITUCIONALES. 6.1 Continuidad parlamentaria. 6.2. Defensa constitucional. 6.3. Administración parlamentaria. 7. FACULTADES DE ACTUACIÓN. 7.1. En orden a su función de garantía constitucional. 7.2. En orden a su función de continuidad. 7.2.1. Facultades en orden a su función de continuidad constitucional. 7.2.2. Facultades en orden a su función de continuidad parlamentaria material. 7.2.3. Facultades en orden a su función de administración parlamentaria. 8. CONCLUSIONES. 


\title{
LA DIPUTACIÓN PERMANENTE EN LA CONSTITUCIÓN DE CÁDIZ O EL INTENTO FRUSTRADO DE CREAR UN ÓRGANO CON FUNCIONES DE GARANTÍA CONSTITUCIONALO
}

POR

\author{
ÁNGEL LUIS ALONSO DE ANTONIO \\ Profesor Titular de Derecho Constitucional \\ Universidad Complutense de Madrid
}

\section{INTRODUCCIÓN}

La aprobación de la Constitución de Cádiz supuso un punto de inflexión en nuestra historia, un hito revolucionario de cambio en la estructura de poder que caracterizaba al Antiguo Régimen. Ahora se trataba de diseñar un nuevo ideario político articulado en torno a los principios de soberanía nacional, división de poderes y representación popular, es decir, se anhelaba una transformación en la forma de concebir el poder y en el modo de su ejercicio. Cuestión distinta es la valoración del resultado de tal empeño porque si bien se ha dicho que «la Constitución de 1812 marca el comienzo de la modernidad en España» ${ }^{1}$ o que «la trascendencia de las Cortes de Cádiz radica en su diseño revolucionario de un nuevo modelo de Estado, el liberal burgués» ${ }^{2}$, otros entienden que el resultado

\footnotetext{
${ }^{1}$ Martínez Sospedra, Manuel, La Constitución de 1812 y el primer liberalismo español, Cátedra Fadrique Furro Ceriol, Facultad de Derecho, Universidad de Valencia, Valencia, 1978, pág. 15.

2 Garófano, R. y Páramo, J. R., La Constitución gaditana de 1812, Diputación de Cádiz, Cádiz, 1983, pág. 25.
} 
no fue tan positivo considerando que las Cortes de Cádiz se convirtieron en el primer ejemplo durante el siglo XIX de una sucesión de fracasos ${ }^{3}$.

Con independencia del valor que se reconozca al texto gaditano y la trascendencia de su irregular aplicación, lo cierto es que la pretensión inicial de los constituyentes era la nueva definición de las instituciones políticas, concediendo una atención preferente al poder legislativo que se atribuía a un órgano unicameral, las Cortes, concebidas según el artículo 27 como «la reunión de todos los diputados que representan a la Nación, nombrados por los ciudadanos...». Se formalizaba constitucionalmente de tal modo el moderno parlamentarismo español cuyo nacimiento fija García Venero el 24 de septiembre de 1810 al constituirse las Cortes Generales en la Isla de León ${ }^{4}$.

La nueva concepción del poder legislativo representa una ruptura radical con las viejas convocatorias a Cortes. Aunque son significativos ciertos datos como la elección mediante sufragio universal masculino de cuatro grados y el abandono del mandato imperativo, en este momento interesa resaltar cuatro ideas esenciales, esto es, la desvinculación de la convocatoria ordinaria de la voluntad del monarca, la periodicidad en la celebración de las Cortes, la duración de sus sesiones y la existencia de períodos de inactividad parlamentaria regulados en la Constitución. No obstante lo anterior hay que subrayar que en la Constitución de 1812 no había una auténtica vacatio parlamentaria porque los constituyentes incorporan en los artículos 157 a 160 un órgano, la Diputación Permanente, que garantiza la continuidad parlamentaria. Se reivindicaba así el método español tradicional de evitar los paréntesis en la representación de los ciudadanos, mediante un órgano específico que se crea en Cataluña a finales del siglo XIII y que para Rubio y Cambronero constituye la institución «más importante que ha creado la España medieval» ${ }^{5}$. Sin perjuicio de las necesarias referencias genéricas a la función del órgano en presencia, en esta sede dedicaremos un énfasis especial a la función que le encomendaba el artículo 160.1 ${ }^{\mathrm{a}}$, es decir, «velar sobre la observancia de la Constitución y de las leyes, para dar cuenta a las próximas Cortes de las infracciones que haya notado» ${ }^{6}$.

3 Témine, E., Broder, A. y Chastagnaret, G., Historia de España contemporánea. Desde 1808 hasta nuestros días, Ariel, Historia, Barcelona, 1982, pág. 13 (Introducción).

4 García Venero, Maximiano, Historia del Parlamentarismo Español, Instituto de Estudios Políticos, Madrid, 1946, pág. 88.

5 Rubio y Cambronero, I., La Deputació del General de Catalunya en los siglos XV y XVI, vol. 1, Diputación Provincial de Barcelona, Barcelona, 1950, pág. 17.

6 En relación al significado de garantía constitucional de la Diputación Permanente en la Constitución de 1812, vid. LORENTE SARIÑENA, Marta, Las infracciones a la Constitución de 1812. Un mecanismo de defensa constitucional, Centro de Estudios Constitucionales, Madrid, 1985, págs. 183-186. 


\section{DENOMINACIÓN}

La Constitución de Cádiz establece un órgano de continuidad parlamentaria con la clásica denominación de Diputación Permanente. Son, en consecuencia, razones de puro mimetismo histórico las que explican su utilización sin que durante el proceso constituyente se razonara el uso de esa expresión.

Aun aceptando el peso de la tradición y el recuerdo del pasado glorioso de la institución que se comenta, respecto a su denominación no se puede dejar de señalar algún comentario crítico. Así, en sentido estricto, no tenía en realidad un carácter permanente ya que su nombramiento se difería al final del período de sesiones y su eficacia funcional abarcaba sólo el limitado período de inactividad parlamentaria. Además, la existencia de esta figura se circunscribía, en principio, entre Cortes ordinarias (art. 159) quedando excluida en consecuencia entre Cortes extraordinarias o entre unas Cortes extraordinarias y las siguientes ordinarias. El citado precepto implicaba una modificación en relación a posturas anteriores sobre el mismo tema. Así, la Junta de Legislación, en su Acuerdo 13 adoptado en Sevilla el 15 de diciembre de $1809^{7}$ fijaba que los componentes de la Diputación Permanente «quedarán en ejercicio durante el intermedio de unas Cortes a otras». Del mismo modo, la Comisión redactora del Proyecto de Constitución en la sesión de 5 de julio de $1811^{8}$ establecía inicialmente en el artículo 3 del Capítulo 10 que «la Diputación Permanente durará de Cortes a Cortes». La posterior limitación en el ejercicio de funciones por el órgano en cuestión a los períodos entre Cortes ordinarias implicaba una discontinuidad en los demás intervalos entre Cortes que la Diputación Permanente no podía colmar.

Las anteriores referencias llevan a pensar que la elección de la denominación Diputación Permanente aplicada al órgano de continuidad parlamentaria no fue demasiado afortunada porque tal vez no lograra expresar nítidamente el propósito que se pretendía con su creación, identificándole además con el objeto mismo que se quería lograr con su reconocimiento constitucional, es decir, ya no se buscaba la permanencia del Parlamento sino la continuidad de su trabajo fuera de su período de funcionamiento regular.

\footnotetext{
7 Acuerdos de la Junta de Legislación. Archivo del Congreso de los Diputados (ACD), Serie General, Leg. 3, exp. 8.

8 Actas de la Comisión nombrada para la formación del proyecto de Constitución. ACD, Papeles reservados de Fernando VII. T. XXV, folio 298.
} 


\section{CONSTITUCIONALIZACIÓN DEL ÓRGANO. SU JUSTIFICACIÓN}

Debe reconocerse ab initio que la necesidad de recoger en la Constitución de Cádiz una figura como la Diputación Permanente no fue asumida con general complacencia, aunque hubiera datos que en principio avalaran la tesis contraria. Así, en la Consulta al país sobre el contenido que habría de tener la futura Constitución numerosos informes defendían su reconocimiento 9 , la Junta de Legislación la menciona durante sus trabajos ${ }^{10}$, la Comisión de Constitución la introduce a lo largo de sus sesiones ${ }^{11}$ y además en ningún momento algún constituyente se opuso a su existencia. No obstante lo anterior, debe afirmarse que durante la discusión constitucional se apreció en ocasiones una indiferencia ante la Diputación Permanente lindante con el ataque directo o incluso la negación de la conveniencia de su reconocimiento. Puede afirmarse por ello que la Diputación Permanente fue algo cuestionado, o al menos escasamente defendido, por ciertos miembros de la Comisión que presentó el proyecto de Constitución porque en la defensa del mismo no argumentaron en rigor sobre las razones que les llevaron a incluir un órgano de esa clase, limitándose a decir que a la Comisión le pareció «oportuno conservar una institución tan nacional y precavida» ${ }^{12}$, incluso, a la vista de las diferencias con épocas anteriores, no tiene reparos en afirmar que ahora «no era tan necesaria la Diputación como cuando todo era más bien tradicional y de costumbre que mandado por leyes claras y terminantes» ${ }^{13}$. Más aún, Argüelles es tajante al señalar posteriormente que «dejaba en rigor de ser necesaria desde que la reunión de Cortes se hiciese regular, anual, sistemática; esto es, establecida por la ley en su forma y autoridad ${ }^{14}$. Resulta paradójico por ello lo que el mismo Argüelles señalaba en

9 Entre otros, los del Obispo de Calahorra, ACD, Serie General, Leg. 6, núm. 27, hoja 3; del Cabildo de Lérida, ACD, Serie General, Leg. 6, núm. 19, hoja 2; Manuel Mohamud, ACD, Serie General, Leg. 6, núm. 30, hoja 9; Manuel Fernández Manrique, ACD, Serie General, Leg. 10, núm. 19, hoja 2; Junta de Mallorca, ACD, Serie General, Leg. 5, núm. 47, hoja 6; Audiencia de Galicia, ACD, Serie General, Leg. 6, núm. 12, hoja 4.

10 Vid. En tal sentido el Acuerdo núm. 13, de 15 de diciembre de 1809 y el Acuerdo núm. 17, de 31 de diciembre de 1809. ACD, Serie General, Leg. 3, exp. 8.

11 Actas de la Comisión nombrada para la formación del Proyecto de Constitución. ACD, Papeles reservados de Fernando VII. T. XXV, folios 267-384. Sesión de 22 de mayo de 1811, folio 287; Sesión de 3 de junio de 1811, folio 290; Sesión de 5 de junio de 1811, folio 291; Sesión de 5 de julio de 1811, folio 298.

12 ArgüElles. L. 1810-1813. T. III. DS núm. 371, 8 de octubre de 1811, pág. 2019.

13 Argüelles. L. 1810-1813. T. III. DS núm. 370, 7 de octubre de 1811, pág. 2013.

14 ArgüElles. L. 1810-1813. T. III. DS núm. 371, 8 de octubre de 1811. Pág. 2019. 
1835 analizando el trabajo de las Cortes en el período 1810-1813 cuando al referirse a una presunta justificación de la Diputación Permanente apuntaba que «para que esta disposición — se refería a la reunión anual de Cortes — no fuese infructuosa se daba a la Diputación permanente de Cortes, facultad de convocarlas en la vacante del Trono, y cuando el Rey se imposibilitase para el Gobierno, o quisiese renunciar a la Corona. La historia de todas las épocas de la monarquía, y los desastres coetáneos no permitían que se dejase a la nación sin las precauciones necesarias contra la ambición doméstica y extranjera. De este modo quedaba prevenido en el caso de poder ser sorprendido el reino, o de verse obligado a recurrir en el peligro a medios desusados y violentos para que se celebrasen Cortes» ${ }^{15}$. Una de las muchas contradicciones de Argüelles a la vista de los debates constitucionales.

Realmente la única razón que justifica el reconocimiento de la Diputación Permanente por parte de la Comisión era el respeto a la tradición española, es decir, un factor exclusivamente histórico porque luego se negó a cualquier ampliación de funciones, el incremento de facultades o incluso el aumento del número de sus componentes. Aun así, cabe reconocer también en este orden un argumento de filosofía política que avalaría el reconocimiento constitucional del órgano que respondería «a la necesidad de salvar los interregnos de Cortes en tal manera que ni un momento deje de actuar e influir el espíritu de aquéllas mediante su encarnación en un grupo de diputados» ${ }^{16}$. En consecuencia, la facultad recogida en el artículo $160.1^{\mathrm{a}}$, señalada anteriormente, quedaba vacía de contenido porque el propio constituyente no la dotó de contenido sustantivo como se verá en su momento.

\section{CARACTERIZACIÓN DUAL DE SU NATURALEZA}

La doctrina ha coincidido en considerar que la Diputación Permanente de la Constitución de 1812 tenía una naturaleza estrictamente jurídica. Sin embargo, el recto entendimiento del propio texto constitucional y sobre todo el ejercicio de las funciones que el órgano desempeñó en la práctica en algunos momentos aconsejan defender el carácter dual de la naturaleza de la institución,

15 ArgüElles, Agustín de, Examen histórico de la Reforma constitucional que bicieron las Cortes Generales desde su instalación en la Isla de León el 24 de septiembre de 1810 hasta que se cerraron en Cádiz el 14 de septiembre de 1813, Carlos Wood e hijo, Londres, 1835, pág. 80.

16 Fernández Almagro, Melchor, Orígenes del Régimen Constitucional en España, Editorial Labor S.A., Barcelona, 1976, pág. 125. 
diferenciando una caracterización jurídica y otra política, en orden precisamente a la garantía de la observancia de la Constitución que el texto gaditano encomendaba a la Diputación Permanente.

\section{A) Naturaleza jurídica}

Es una idea común en los autores referirse a la Diputación Permanente como Comisión de continuidad parlamentaria ${ }^{17}$. En el caso en presencia, es discutible la atribución del carácter de Comisión a la Diputación Permanente de 1812 a la vista de que los Reglamentos de las Cortes de 1813 y 1821 señalaban con claridad cuáles eran las Comisiones particulares que habían de formarse en la Cámara (arts. 80 y 85 respectivamente) que no incluían a la Diputación Permanente. Es cierto que el último de los artículos citados añadía que las Comisiones que mencionaba «se podrán aumentar si la multitud y gravedad de los negocios lo exigiere». Sin embargo, la Diputación Permanente tenía, primero en la propia Constitución y luego en los Reglamentos citados, una existencia autónoma que impide aplicarle sin más el mero carácter de Comisión.

Aceptado el carácter singular del órgano, y aunque sea obvio entender la Diputación Permanente como órgano de continuidad parlamentaria, esa caracterización resulta parcial y por ende incompleta porque la figura que se comenta presentaba una complejidad que aconseja diferenciar una naturaleza jurídica plural.

En primer lugar, y en orden a lo que se acaba de apuntar, la Diputación Permanente de la Constitución de 1812 era un órgano de continuidad parlamentaria desde una doble perspectiva: continuidad formal, produciéndose una ficción jurídica por la que un órgano reducido asume la representación entera de la Cámara y en consecuencia no se produce vacío de la representación nacional; y continuidad material, al encargarse el órgano por mandato constitucional y reglamentario de la preparación e instrucción de los expedientes que debían presentarse a las futuras sesiones, recibía a los nuevos diputados, etcétera.

En segundo lugar, la Diputación Permanente era un órgano de administración y gobierno parlamentario puesto que a través de los Reglamentos se equiparaban las funciones de la Comisión de Gobierno interior del edificio de la Cámara y la Diputación Permanente, según que las Cortes se encontraran o no en período de se-

17 Así, v. gr. Alonso de Antonio, José Antonio, «La Diputación permanente en el sistema parlamentario español», en Revista de las Cortes Generales, núm. 8, segundo cuatrimestre, 1986, pág. 141; Fraile Clivillés, Manuel, La Comisión Permanente de las Cortes, Editora Nacional, Madrid, 1974, pág. 49; Ruiz LapeÑa, Rosa Ma , El Tribunal de Garantías Constitucionales en la II República Española, Bosch, Barcelona, 1982, pág. 4. 
siones. Así, el artículo 182 del Reglamento de 1813 establecía la existencia de un Inspector Arquitecto encargado de la conservación y seguridad del edificio de las Cortes proponiendo las obras necesarias a tal efecto «a la Comisión encargada del gobierno interior del mismo edificio, o a la Diputación permanente, si las Cortes no estuvieran reunidas». Más explícitamente aún, los artículos 186 del Reglamento de 1813 y 220 del Reglamento de 1821 señalaban ab initio que «el orden y gobierno interior del edificio de las Cortes estará a cargo de la Diputación permanente». Los citados artículos ponían bajo su autoridad las oficinas y subalternos de las Cortes aunque sin capacidad para deponer a los funcionarios sino tan sólo de suspenderlos con justa causa poniéndolo en conocimiento de las Cortes cuando se reunieran de nuevo. En consecuencia, asumiendo la acertada expresión de Pérez Serrano, puede decirse que «cuando el ritmo de los acontecimientos es el habitual, actúa como organismo administrativo» ${ }^{18}$.

En tercer lugar, por último, pero no menos importante porque es un punto central del presente comentario, la Diputación Permanente de 1812 era un órgano de garantía constitucional. La discusión en torno a la Diputación Permanente durante la elaboración constitucional se centró de forma muy notable en la posibilidad de que se le encomendase la función de velar por la observancia de la Constitución. No resulta por ende exagerado entender que ello "parece ser una insinuación del futuro sistema de garantías constitucionales» ${ }^{19}$. Resulta obvio que no puede atribuirse a la Diputación Permanente de la época el carácter de Tribunal Constitucional al estilo kelseniano, pero es importante subrayar que aunque sea con un carácter instructorio, a veces superado por la fuerza de los acontecimientos que hizo necesario que la Diputación Permanente adoptara unos comportamientos que iban más allá de lo que fijaba la letra de la Constitución pero que sin duda tenían acomodo en su espíritu, fuera a este órgano a quien se encomendase esta garantía.

\section{B) Naturaleza política}

Al hilo de lo que acaba de manifestarse, puede decirse que la Diputación Permanente no se limitó en su funcionamiento a ser el aséptico órgano jurídico con facultades tasadas sino que en ocasiones adoptó una postura beligerante ra-

18 Pérez Serrano, Nicolás, «La Diputación permanente de Cortes en nuestro Derecho Constitucional Histórico» (AHDE 1932), en Escritos de Derecho Político I, Colección `Administración y ciudadano’, Instituto de Estudios de Administración Local, Madrid, 1984, pág. 195.

19 SÁnchez Goyanes, Enrique, Constitución española comentada, Paraninfo S. A., Madrid, 1980, pág. 19 
yando incluso en la intromisión en asuntos de la política general de la nación. Baste recordar, en este sentido, los acontecimientos de noviembre de 1820 y de julio de 1822.

Los primeros fueron originados por la que Tuñón de Lara considera «una especie de golpe de Estado» ${ }^{20}$ al pretender el Rey nombrar, al margen de lo previsto en la Constitución, al teniente general José María Carvajal como Capitán General de Castilla la Nueva. Los primeros datos que recibió la Diputación Permanente sobre este hecho no la predispuso contra el monarca viéndose en tal nombramiento «ejecución de los planes y maquinaciones de los malvados, que seduciendo el inocente corazón del Rey, tratan de minar el edificio social, atacando el cimiento de su prosperidad que es la Constitución» ${ }^{21}$. Aun así, la Diputación Permanente acordó preguntar a los Secretarios de Estado sobre las noticias que ellos tuvieran, quedando desde ese momento reunida hasta recibir contestación que llegó de las Secretarías de Gobernación de la Península, de Gracia y Justicia y de Hacienda, según la cual el Rey acababa de nombrar a Carvajal por una carta particular, sin autorización del Secretario del Despacho correspondiente vulnerando por ello el artículo 225 de la Constitución lo que implicaba su vulneración expresa. El hecho de que tal circunstancia se produjera en el campo de la milicia lo interpreta Blanco Valdés como «un pulso al poder de representación de la nación y lo había planteado donde se consideraba podía serle ventajoso: en el ámbito del poder militar» ${ }^{22}$. Relataban los Secretarios su visita a la Secretaría de la Guerra donde el propio Carvajal les mostró una carta confidencial del Rey, al parecer toda de su puño y letra, en la que le instaba a que inmediatamente tomase el mando avisándole de haberlo hecho. El entonces Capitán General, Gaspar de Vigodet había recibido también, a través de un Garzón de Guardias de la Real Persona, un pliego escrito por el Rey ordenándole que por haberle nombrado Consejero de Estado entregase el mando a Carvajal.

Ante la confirmación de las primeras noticias, la Diputación Permanente se constituyó en órgano de defensa constitucional, acordando como primera medida elevar una exposición, redactada en el acto y remitida a las cinco de la tarde del día 16 de noviembre por medio extraordinario mediante oficio al Secretario

20 TuÑón DE LARA, Manuel, La España del siglo XIX, Editorial LAIA, 11 a edición, Barcelona, 1977, vol. I, pág. 70.

${ }^{21}$ Volumen Sesiones de las Cortes. Actas Secretas 1820-1823. Tomo único, dentro del acta de la sesión de 16 de noviembre de 1820 que comprende hasta la del día 18.

22 BlanCo VAldés, Roberto L., Rey, Cortes y fuerza armada en los orígenes de la España liberal, 1820-1823, Institució Valenciana d’Estudies i Investigació, Siglo XXI editores, Madrid, 1988, pág. 325. 
del Despacho de Marina para que la hiciese llegar al Rey de forma personal e inmediata. En ella se podía ver un esbozo de su cometido como órgano político garante de la estabilidad institucional pues si bien en un primer momento la Diputación Permanente «se abstiene, por respeto, de hacer a V. M. las reflexiones que le excita este extraordinario suceso, contrario a un artículo de la Constitución...» ${ }^{23}$, a renglón seguido no deja lugar a dudas de su inmediata intención, creyendo «indispensable que no se coloque en los principales destinos públicos sino a personas que inspiren una entera y cabal confianza por su acreditada adhesión al sistema constitucional, pero no puede menos la Diputación de hacer presente a V. M. que, respetando su sagrada Persona, declarada inviolable por la Constitución, no mirará con indiferencia que se infrinja de manera alguna esta ley fundamental, ni que ningún español falte al juramento que ha prestado de cumplir religiosamente sus preceptos; y puesto que se halla encargada de un depósito tan sagrado, no verá aparecer el menor riesgo que amenace el régimen constitucional adoptado por V. M. y la Nación entera, sin poner en práctica todo el lleno de sus legítimas facultades, para cumplir con la primera de sus obligaciones, que es salvar el Estado» ${ }^{24}$.

La inquietud del ánimo popular aconsejó a los rectores del gobierno municipal tomar las medidas necesarias para conservar la tranquilidad pública que se vio incrementada por el compromiso de la guarnición de la plaza y de la Milicia Nacional de guardar la Constitución frente a las órdenes recibidas contrarias a la misma. La Diputación Permanente decidió dar cuenta al pueblo y al resto de los diputados de las iniciativas que estaba tomando por lo que se abrió el edificio donde estaba reunida pasando todos al salón de sesiones donde el Secretario dio lectura al acuerdo que se acababa de tomar en los siguientes términos ${ }^{25}$ :

«Reunidos a la siete de esta noche los señores individuos de la Diputación Permanente que se citan al margen, se advirtió que había en el pueblo una grande efervescencia, que pedían a grandes gritos la reunión de las Cortes extraordinarias, para que éstas tomasen providencias sobre el nombramiento que sabían haberse hecho en D. José Carvajal para capitán general de esta provincia, sin guardarse las formalidades prescritas en la Constitución. En consecuencia, la Diputación, tomadas todas las medidas que creyó propias de sus atribuciones, y oídos los pareceres de muchos de los Sres. Diputados que se hallaban en la Secretaría, con el deseo de evitar los males que amenazaban, acordó trasladarse a la sala de Cortes en sesión pública con el fin de manifestar a los Sres. Diputados que se hallen presentes, y al pueblo, las ocurrencias de este día, las medidas que se habían

23 Acta de la sesión del 16 de noviembre, op. cit., pág. 50.

${ }^{24}$ Ibídem.

${ }^{25}$ Ibídem, págs. 50-51. 
tomado para asegurar la libertad de la Patria, y la firme resolución en que está de continuar tomando las más enérgicas y eficaces, siempre que así lo exija la salud del Estado».

El Ministro interino de la Guerra informó a la Diputación Permanente de que había recibido la orden del Rey para el nombramiento de Carvajal que, sin embargo, no había cumplimentado haciendo llegar además al Rey por conducto del Secretario de Marina las razones de su conducta ${ }^{26}$. Al tener conocimiento de estos hechos, la Diputación Permanente deliberó con los Secretarios del Despacho y con las autoridades de Madrid, decidiendo elevar a las dos y media de la noche una segunda exposición al Rey por el Secretario de Despacho de marina, en la que se le expresaba «la conveniencia y necesidad de que se restituya al seno de este heroico pueblo... que no puede estar tranquilo mientras vea fuera de sus muros, y sin causa conocida, a su augusto Monarca. También ruega la Diputación a V. M. que... aleje de su lado a las personas que siempre han abusado y abusan de la bondad de V. M...» ${ }^{27}$. Se recibió contestación regia a la primera exposición en los siguientes términos ${ }^{28}$ :

«Señores de la Diputación Permanente: Conociendo a fondo los límites de la autoridad que la Constitución me da, y el modo con que debo ejercerla, no fue mi ánimo al expedir los avisos confidenciales que di para reemplazar en el mando al capitán general de Castilla la Nueva, el que se llevasen a efecto hasta que fuese comunicada la orden por el Secretario del Despacho de la Guerra, a quien se le ha comunicado con este objeto, como ya tendría noticia de ello la Diputación. Resuelto a cumplir en todas partes el pacto solemne que he jurado, la Nación no me verá desviarme ni un ápice de la senda constitucional; debiendo quedar tranquila de todo punto la Diputación en la rectitud de mis intenciones».

Lejos de tranquilizar, la respuesta aumentó los temores populares al confirmarse el nombramiento de alguien que tanto rechazo había suscitado. Algunos militares como el Marqués de las Amarillas o el jefe de escuadra Fernando Casado de Torres se ofrecieron a la Diputación Permanente en apoyo de su propósito de defensa de la Constitución. La ausencia de respuesta a la segunda exposición y el aumento de la intranquilidad social motivó la redacción a las cuatro de la tarde del día 17 de una tercera con un espíritu más radical que las anteriores, «conminatorio» ${ }^{29}$ incluso, incluyendo la solicitud de que alejase del entorno del

26 Ibidem, pág. 51.

27 Ibidem.

28 Ibidem, pág. 58.

29 Blanco Valdés, Roberto L., op. cit., pág. 327 
Rey al mayordomo mayor, al confesor y a todas las personas desafectas al régimen constitucional, la necesidad de que el Rey solicitase a la Diputación Permanente la convocatoria de Cortes extraordinarias y la amenaza de utilizar el artículo 162.2, es decir, la declaración de imposibilidad del monarca para el ejercicio de sus funciones ${ }^{30}$. La dureza de las medidas planteadas y el escaso eco de las órdenes reales en el estamento militar y en los órganos de dirección política, explican las siguientes contestaciones del monarca. A la segunda exposición que recibe, responde con la anulación del nombramiento de Carvajal y el anuncio de su vuelta a Madrid $^{31}$. A la tercera, con la separación de las personas implicadas y su aceptación de la convocatoria de Cortes extraordinarias siempre que, con arreglo al artículo 163 de la Constitución, se determinara el objeto único para el que debían convocarse $^{32}$.

El pulso estaba perdido, por ahora, para el Rey y permitía apuntar como conclusión que en la práctica funcionaba «un sistema parlamentario, en el que el centro de representación de la nación se constituía en centro de la dinámica social» ${ }^{33}$. Ello, aunque cierto, no debe hacer olvidar otro de los factores decisivos en aquellos momentos, el decidido posicionamiento de los militares al lado de la Constitución. En otros períodos del reinado de Fernando VII la actitud no fue la misma y el resultado tampoco.

Más importantes fueron, si cabe, las jornadas de julio de 1822. El origen mediato de aquellos acontecimientos se localiza para Pérez Garzón «desde el 30 de mayo de 1822, onomástica del Rey, en que se oyen gritos absolutistas en Aranjuez, hasta el 30 de junio, clausura de las Cortes, en que la Guardia Real vuelve a proferir los mismos gritos» ${ }^{34}$. El detonante directo aparece, en opinión de Sevilla Andrés, en la conspiración «organizada por el realista Luis Fernández de Córdova» ${ }^{35}$. El primer indicio de una situación anómala lo tiene la Diputación Permanente el 2 de julio cuando el oficial de la Guardia de Palacio de las Cortes

30 Acta de la sesión del día 16 de noviembre, op. cit., pág. 53.

31 Ibídem, pág. 55.

32 Ibidem.

33 Blanco Valdés, Roberto L., op. cit. pág. $327 .$.

34 Pérez GArzón, Juan-Sisinio, «Los acontecimientos del 7 de julio de 1822. Datos para un análisis socio-político», en Anales del Instituto de Estudios Madrileños, Tomo XI, Madrid, 1975, pág. 221. Sobre estos antecedentes puede verse también Comellas GARCÍA-LLERA, José Luis, El trienio constitucional, Rialp, Madrid, págs. 336-339.

35 SEvilla Andrés, Diego, Historia constitucional de España (1800-1966), Escuela Social, Valencia, 1966, pág. 57. Tras analizar las diversas hipótesis sobre el tema, Comellas recoge las palabras del propio FERnÁndez de Córdova asumiendo la paternidad de la intentona (Comellas García-Llera, José Luis, op. cit., pág. 340). 
comunica que aproximadamente a las siete de la mañana de ese día abandonó el puesto la tropa que estaba bajo su mando dirigiéndose al Palacio Real para unirse a los que guardaban aquel lugar. Acordó la Diputación Permanente recabar noticias oficiales para confirmar primero y conocer después el alcance real de lo sucedido. Entre tanto, recibió un oficio del Secretario del Despacho de la Guerra haciendo llegar a la Diputación Permanente el desagrado del Rey por lo sucedido así como la confirmación de que la «Diputación permanente puede estar tranquila acerca de la independencia en que conviene se hallen el Rey y el gobierno para mandar con todo el lleno de las facultades que les competen por la ley fundamental del Estado, pues que están en absoluta libertad de obrar con la precisión y energía necesaria a mantener la tranquilidad pública y hacerse respetar» ${ }^{36}$. Ese mensaje tranquilizador no evitó que la Diputación Permanente mandase al Rey otra exposición haciéndole ver lo difícil de la realidad en Madrid que sin duda se agravaría en la hipótesis de ausencia regia de la capital indicando además que de no tomarse las medidas adecuadas para solucionar la situación, «en otro caso, que no es de esperar, la Diputación, puntual observadora de las leyes fundamentales, se verá en la precisión de adoptar las providencias que en las mismas se hallan determinadas» ${ }^{37}$.

Vuelven a plantearse, aunque con un carácter claramente preventivo, los recelos poder legislativo-poder ejecutivo, así como una interpretación patriótica de la Constitución por parte de la Diputación Permanente. El recuerdo de su «victoria» en 1820 afianzaba de partida su posición. El Rey, por medio del Secretario del Despacho de Gracia y Justicia hizo llegar su respuesta a la Diputación Permanente ${ }^{38}$ reiterando su pesar por los acontecimientos y la intención de tomar todas aquellas medidas conducentes a resolverlos, entre las que se encontraba el nombramiento del teniente general Pablo Morillo, conde de Cartagena, como coronel interino de la Guardia Real. El día 3 trascurrió sin novedad destacada. El 4 se decide el envío de una nueva exposición al Rey solicitándole que salga de aquel Palacio rodeado de fuerzas hostiles a la Constitución y se ponga al lado del pueblo madrileño que lucha por su libertad, porque los hechos conocidos hasta entonces «persuaden a la Diputación no hallarse V. M. con toda la libertad y seguridad que debe tener el Rey de las Españas» ${ }^{39}$. La incertidumbre hizo que el Ayuntamiento propusiera a la Diputación Permanente que variara de local al objeto de garantizar en mayor grado su seguridad, medida que no fue

\footnotetext{
${ }^{36}$ Actas Secretas 1820-1823. Acta del día 2 de julio de 1822, pág. 440.

37 Ibídem, pág. 441.

38 Ibídem, págs. 441-442.

39 Acta del día 4 de julio de 1822, op. cit., pág. 444.
} 
contemplada como necesaria "porque ningún punto podría ofrecer mayor seguridad que el santuario de las leyes» ${ }^{40}$. El día 5 se envía una nueva exposición al Rey ${ }^{41}$ recordando los puntos de las anteriores al tiempo que se le solicita que escuche al Consejo de Estado para que con su dictamen se tomen las medidas adecuadas a las circunstancias. El Rey contestó por medio del Ministerio de Gracia y Justicia indicando que el Consejo de Estado creía como paso ineludible la retirada de los cuatro batallones sublevados a sus puntos de origen, orden que de inmediato cursó el Rey ${ }^{42}$. El comandante de los batallones manifestó por el contrario «que no podían llevar a efecto lo mandado por S. M. supuesto que no se le daban ningunas seguridades, y que resueltos a morir con honra desde que salieron de sus cuarteles, no podían prestarse a una muerte por otra parte segura y vergonzosa» ${ }^{43}$. Una nueva exposición al $\mathrm{Rey}^{44}$ comunicándole esos comentarios y poniéndole en antecedentes de las decisiones que pudiera adoptar la Diputación Permanente si él mismo no dictaba las órdenes oportunas, dejan clara la gravedad del momento y la posibilidad real de un nuevo enfrentamiento entre el Rey y las Cortes que si bien estaba latente durante los días anteriores, el respeto y la paciencia de la Diputación Permanente quería evitar a toda costa.

En la madrugada del día 7, los cuatro batallones se desplazaron desde el Palacio del Pardo a Madrid, dejando el Palacio y por tanto al Rey incomunicado con la capital ${ }^{45}$. La trascendencia del hecho se hace evidente si consideramos la significación de la Guardia Real, para Carr, «el factor aislado más importante de la política revolucionaria puesto que podía arrancar el control de las calles a la Milicia, cuerpo formado para defender una Constitución que era el símbolo de la esclavitud del Rey» ${ }^{46}$. Se envió una nueva exposición al Rey en la que rogaba «encarecidamente a V. M. se coloque en términos de poder ser custodiado por tropas fieles.. No tomando, Señor, esta medida en el instante, la Diputación se ve precisada, sin pasar de hoy, a convocar Cortes extraordinarias según lo literal del artículo 162 de la Constitución oyendo para ello al Consejo de Estado, y entregar las riendas del Gobierno a una Regencia, como igualmente en ella se pre-

40 Acta del día 5 de julio de 1822, op. cit., pág. 446.

41 Ibidem.

42 Acta del día 6 de julio de 1822, op. cit. pág. 447.

43 Ibídem, pág. 448.

44 Ibidem.

45 Sobre la noche del 6 al 7 de julio de 1822 puede verse una detallada narración en COMELLAS García-Llera, José Luis, op. cit., págs. 344-348. Esa jornada del 7 de julio fue, para Carr «culminación del descontento de la Guardia Real (Carr, Raymond, España, 1808-1939, Editorial Ariel, 6a reimpresión, Barcelona, 1978, pág. 142).

46 CARr, Raymond, op. cit., pág. 142. 
viene» ${ }^{47}$. Convocó al Consejo de Estado quien en su dictamen sostuvo que «si continuando S. M. custodiado por los batallones de la Guardia Real de infantería, no saliese a paraje libre, se halla en el caso de inhabilidad moral de que trata el artículo 162 de la Constitución» ${ }^{48}$. Recibido el dictamen por la Diputación Permanente y enterada ésta de que las circunstancias habían cambiado estando ya el Rey en plena libertad, acordó que no se deliberase la consulta del Consejo de Estado, levantándose la azarosa sesión del 7 de julio ${ }^{49}$.

La simple constatación de las actuaciones de la Diputación Permanente ante acontecimientos de la importancia política como los que se acaba de relatar reafirman la idea de atribuir un marcado carácter político al órgano de continuidad parlamentaria, asumiendo la opinión de Pérez Serrano en el sentido de que «si la paz se altera, y el sistema constitucional corre peligro, la Diputación sale de su atonía, se coloca a la cabeza de todos los poderes y magistraturas; reta y humilla, si es necsario, al Monarca; somete al Gobierno, ordena al Consejo de Estado y esgrime como instrumento persuasivo sus aceradas exposiciones, y como arma decisiva la amenaza de convocar Cortes extraordinarias. Trátese, pues, de una Comisión administrativa que, en ocasiones, se transforma en el primer órgano político de la Nación» ${ }^{50}$. Resulta evidente que la Diputación Permanente desbordó en ocasiones con sus actuaciones el limitado diseño que dibujaba el marco constitucional sobre sus atribuciones pero hay que entender que el texto de 1812 era

47 Volumen Sesiones de las Cortes. Actas Secretas, 1820-1823. Tomo único, Sesión del día 7 de julio de 1822, pág. 449. Señala García Venero que esta Regencia fue pedida a la Diputación Permanente por el Duque del Parque, Riego, Beltrán de Lis, Alcalá Galiano y otros muchos (GArcía Venero, Maximiano, op. cit., pág. 450). La Regencia era para Carr el medio de expresión de la voluntad claramente comprobada desde el primer momento de que «la Comisión permanente de las Cortes, el Ayuntamiento (de Madrid) y la milicia estaban decididos a oponerles resistencia (a los miembros de la Guardia Real)», Carr, Raymond, op. cit., pág. 142.

48 Volumen Sesiones de las Cortes. Actas Secretas, op. cit., pág. 450.

49 Es preciso señalar la escasa atención prestada por la doctrina a la intervención de la Diputación Permanente en estos sucesos. Así, por ejemplo, La Rosa se refiere a los hechos del día 6 de julio sin hacer ninguna mención al órgano de continuidad (La Rosa, Tristán, España contemporánea. Siglo XIX, Editorial Destino, Barcelona, 1972, pág. 91). La omisión resulta más palpable aun en el trabajo de Pérez Garzón para quien sólo «la enérgica postura del Ayuntamiento de Madrid que se declara en sesión permanente asumiendo el control de la capital, y la movilización de las masas populares a través de la Milicia Nacional impidieron en aquel momento el retroceso político al absolutismo. A la acción de ambas instituciones -Ayuntamiento y Milicias- se añade la de los cuerpos de la Guarnición y la de otras fuerzas ciudadanas organizadas ad hoc» (PÉrez GARzón, Juan-Sisinio, op. cit., pág. 222). Del mismo modo, para Comellas «durante los sucesos de julio de 1822 fue la milicia la que, literalmente, salvó al régimen constitucional» (COMELlas GARCía-LLERA, José Luis, op. cit., pág. 123).

50 Pérez Serrano, Nicolás, op. cit. pág. 191. 
un intento loable, pero inmaduro, de articular al más alto nivel normativo unos mecanismos eficaces que hicieran posible el establecimiento de verdaderos sistemas de control político y en definitiva de garantía de respeto a la Constitución. El órgano de continuidad, pues, se constituyó, de facto, en garante de la Constitución al ser la representación legítima de la soberanía nacional en períodos de inactividad parlamentaria.

\section{CARACTERÍSTICAS}

Como rasgos que identifican a la Diputación Permanente de la Constitución de 1812 se pueden apuntar:

\section{A) Carácter bistórico}

Como se señaló con anterioridad, la Diputación Permanente en cuanto órgano de las Cortes tiene un carácter netamente español, en concreto su nacimiento se produce en la Cataluña medieval. La Constitución de Cádiz incorpora la figura con un sentido moderno, pero no la crea ex novo. Este es el sentido que cabe atribuir a las palabras de Solé Tura y Eliseo Aja cuando sostienen que la Diputación Permanente en esta Constitución es una «institución original» ${ }^{51}$. La originalidad ha de entenderse referida a los antecedentes históricos que se localizan en nuestro pasado. No cabe señalar sin más que la Diputación Permanente es una creación de la Constitución de Cádiz, pues ello significaría olvidar la tradición histórica y desconocer el hecho de que la Constitución es intrínsecamente original, como reconocen los citados autores al señalar que «el rasgo primero que debemos considerar es la naturaleza misma del proyecto político: la Constitución de 1812 es importante en sí misma por ser el comienzo del constitucionalismo español» ${ }^{52}$. La tradición histórica de la figura no implica sin embargo que pueda admitirse sin más la consideración de Martínez Sospedra en el sentido de que «la Constitución establece la existencia de una Diputación Permanente a imagen y semejanza de la institución tradicional»53. Diferente era el modo de su elección, se incorporan representantes de Ultramar y ahora se dibuja un nuevo modelo de funciones desapareciendo, a modo de ejemplo, la recauda-

51 Solé Tura, Jordi y Aja, Eliseo, Constituciones y períodos constituyentes de España (18001936), Siglo XXI, Madrid, 1977, pág. 17.

52 Ibidem, pág. 19.

53 Martínez Sospedra, Manuel, op. cit., pág. 326. 
ción y administración de tributos que era característica de sus precedentes medievales.

\section{B) Sentido progresista}

La existencia de la Diputación Permanente en las Cortes Medievales implicaba ya el propósito de que la labor de las Cortes supusiera un anhelo de libertad. Ese mismo deseo impregna la institución en 1812 como garante de la continuidad parlamentaria intersesiones ${ }^{54}$. Se deposita en ella la defensa de los derechos nacionales conquistados, se la considera por la Nación el «cuerpo conservador y custodio de sus derechos y libertad» ${ }^{55}$. Su fundamento radicaba en asumir la representación nacional mientras las Cortes no funcionan, en la custodia del propio texto constitucional frente a las violaciones que se pretendieran del mismo, en la convocatoria de las Cortes en aquellas circunstancias que el interés patrio lo demandara por encima de la voluntad discrecional del poder ejecutivo. Se pretendía que fuera, en definitiva, «el eslabón que uniera la cadena con que debía quedar aherrojado para siempre el despotismo» ${ }^{56}$.

\section{C) Espíritu de control}

Parece evidente que «los poderes del monarca en la Constitución están inspirados por la desconfianza ante el posible retorno del absolutismo» ${ }^{57}$. Por lo mismo, en el texto se articulan una serie de medidas tendentes a privar al Rey de

54 Por esa razón la figura ha merecido de la doctrina referencias favorables. Así, «en el funcionamiento de las Cortes, la Diputación permanente desempeña un papel relevante», MERINO Merchán, José Fernando, Regímenes políticos españoles, Tecnos, Madrid, 1988, pág. 51; «mecanismo eficaz para fortalecer aún más al órgano titular del poder legislativo», ToMÁs y VALIENTe, Francisco, Manual de Historia del Derecho Español, 4ª ed., Tecnos, Madrid, 1983, pág. 440; «utilísima institución», Sevilla Andrés, Diego, «La Presidencia del Congreso de los Diputados (18101936)», en Revista del Instituto de Ciencias Sociales, núm. 14, 1969, pág. 48. La Diputación Permanente era para Comellas garantía del «buen funcionamiento de los resortes sobre los que se va a asentar el nuevo régimen» (Comellas García-Llera, José Luis, «Las Cortes de Cádiz y la Constitución de 1812», en Revista de Estudios Políticos, núm. 126, nov-dic. 1962, pág. 101).

55 Escrito de Antonio Capmany, recogido en Castro, Adolfo de, Cortes de Cádiz, Complementos de las Sesiones verificadas en la Isla de León y en Cádiz, tomo I, Imprenta de Prudencio Pérez de Velasco, Madrid, 1913, pág. 485.

56 Discurso pronunciado por el Presidente de la Diputación Permanente en la Sesión del día 15 de septiembre de 1813. El texto puede verse en Castro, Adolfo de, op. cit., pág. 133.

57 Solé Tura, Jordi y AJa, Eliseo, op. cit., pág. 17. 
aquellos espacios discrecionales de los que disfrutaba históricamente. Resulta obligado señalar a la Diputación Permanente como una de ellas, y en ese sentido su establecimiento era para Palacio Atard revelador «de la desconfianza de las Cortes hacia las posibles veleidades absolutistas del monarca» ${ }^{58}$. Con la constitucionalización de esta figura se reforzaba, en suma, el significado central de las Cortes en el diseño del nuevo orden político. Ahora bien, es preciso establecer con precisión el sentido de su labor y en ese orden pueden utilizarse dos perspectivas. Por un lado, de modo radical y un tanto exagerado, se ha llegado a decir que la Diputación Permanente de la Constitución de 1812 supuso crear «al lado del trono un poder rival» ${ }^{59}$. La segunda, que parece más adecuada, significaría, en palabras de Artola, crear «frente al poder ejecutivo una Diputación permanente de Cortes» ${ }^{60}$ pero no en el sentido de institucionalizar un enfrentamiento crónico entre órganos constitucionales del Estado, que sólo produciría distorsiones del propio orden político que se quería reforzar. Se pretendía tan sólo hacer respetar el principio de división de poderes articulando las defensas oportunas para ello. Sería por tanto, en palabras de Palacio Atard, «más un efecto psicológico que una verdadera disputa de poder» ${ }^{61}$, aunque como se vio con anterioridad llegado el caso de infracción de la Carta Magna por el monarca, la Diputación Permanente se erige en órgano de defensa constitucional y no duda en cuestionar la autoridad real obligándole a respetar los límites que el texto de 1812 fijaba a su autoridad.

\section{SU COMETIDO. FUNCIONES CONSTITUCIONALES}

Cuando se aborda el tema de las funciones que la Constitución de Cádiz atribuía a la Diputación Permanente hay que partir de la dialéctica entre una interpretación extensiva o restrictiva sobre el entendimiento general de la institución. En efecto, ese recelo que se mencionó con anterioridad se va a concretar jurídicamente en el propósito de algunos constituyentes de fijar el ámbito de actuación del órgano de forma muy limitada haciendo difícil la posibilidad de una interpretación flexible, potestativa o ampliable en el futuro. En este orden son sufi-

58 Palacio Atard, Vicente, La España del siglo XIX. 1808-1898, Espasa-Calpe, Madrid, 1978, pág. 72 .

59 Diccionario de Historia de España, dirigido por GERMÁN BleIBERG, Alianza Editorial, Madrid, 1981, pág. 957.

60 Artola Gallego, Miguel, Partidos y programas políticos, 1808-1936, tomo I, $1^{\mathrm{a}}$ ed., Cultura e Historia, Aguilar, Madrid, 1977, pág. 178.

61 Palacio Atard, Vicente, op. cit., pág. 72. 
cientemente expresivas las palabras del diputado Argüelles para quien las funciones de la Diputación Permanente no debían «nunca extenderse a ejercer actos de soberanía o en que haya de intervenir la voluntad general de la nación ${ }^{62}$. Tal afirmación colisiona directamente con el sentido propio del órgano, esto es, representar la soberanía nacional cuando las Cortes no estaban en funcionamiento ordinario. Esa prevención sólo puede explicarse bien por su entendimiento incorrecto del instituto de la representación o bien por su secular rechazo de lo que suponía introducir en el texto constitucional la figura de la Diputación Permanente. Esta segunda posibilidad es legítima y por tanto asumible. Aquello es peligroso y claramente incorrecto desde el punto de vista constitucional. Jurídicamente ha de entenderse que cada diputado, desde el momento es que es elegido, se convierte en representante de la Nación en su conjunto y no sólo de aquellos que le han votado o de la circunscripción en la que ha sido elegido. En consecuencia, esa «voluntad general de la Nación» no puede identificarse con la suma aritmética del conjunto de diputados, sino que ha de entenderse formada intelectualmente por la aportación de cada uno de ellos individualmente considerado. Defender por ello que la Diputación Permanente no representaba a la Nación es incorrecto porque sería tanto como reconocer que durante los períodos de inactividad parlamentaria, la Nación no tenía voluntad o incluso que no existía.

Frente a esa visión estricta en cuanto al reconocimiento de funciones de la Diputación Permanente, se hizo patente en algunos constituyentes un propósito de ampliarlas respecto al texto de la Comisión encargada de redactar el Proyecto constitucional. En este sentido debe señalarse, en primer lugar, la extraña caracterización que algunos diputados hacen de lo que denominan el «objeto» de la Diputación Permanente, término que según el contenido que parecen querer atribuirle se identificaría con el de funciones. Ahora bien, la interpretación in extenso de ese «objeto» no resulta convincente ni se ajusta al propósito de este análisis, es decir, destacar la labor de la Diputación Permanente como órgano de garantía constitucional. En efecto, estos diputados de referencia pretendían ampliar las facultades del órgano de continuidad parlamentaria abarcando tareas ejecutivas, interviniendo «en los ramos de la administración pública» ${ }^{63}$, tareas económico-fiscalizadoras conociendo de las «rentas del Estado» ${ }^{64}$, labores de impulso

${ }^{62}$ Legislatura 1810-1813. Tomo III. Diario de Sesiones núm. 362, 29 de septiembre de 1811, pág. 1952.

63 En tal sentido Polo, Legislatura 1810-1813. Tomo III. Diario de Sesiones núm. 370, 7 de octubre de 1811, pág. 2012.

64 Polo, ibídem. 
en el terreno económico debiendo atender «el fomento de las fábricas, de la agricultura, del comercio, etc.» ${ }^{65}$, incluso las funciones propias del gobierno interior de las provincias ${ }^{66}$.

Dejando al margen estas visiones deformadas de las funciones de la Diputación Permanente en la Constitución de Cádiz, éstas pueden sintetizarse en las siguientes:

\subsection{Continuidad parlamentaria}

Heredera de las antiguas diputaciones de los reinos hispánicos medievales, la Diputación Permanente de la Constitución gaditana es el órgano de continuidad en los períodos de inactividad parlamentaria. Ese es el espíritu del artículo 157 del texto, así como el del Discurso Preliminar al presentarse su Proyecto cuando se afirmaba que «en el intervalo que medie entre las sesiones de las Cortes quedará en ejercicio una Diputación de las mismas con facultades señaladas para algunos casos, cuya importancia se recomienda por sí misma sin necesidad de más aclaración $»^{67}$.

El Secretario Oliveros manifiesta al inicio de la discusión parlamentaria del artículo 157 que «este artículo se entiende respecto de las Cortes ordinarios, no de lo que pueda disponer el Congreso de estas y otras sucesivas extraordinarias» ${ }^{68}$. Abundando en esta idea, el artículo 159 de la Constitución establece el período de actividad de la Diputación Permanente «de unas Cortes ordinarias a otras». En su virtud la existencia de la Diputación Permanente y por ello de la continuidad parlamentaria que la misma debiera implicar en cualquier caso, se ve limitada a una situación específica, dejándose para el supuesto de las Cortes extraordinarias libertad a las mismas para para que establezcan o no un criterio a seguir para asegurar la continuidad parlamentaria. Ello implicaba un peligro añadido a la ya señalada desconfianza de algunos hacia la Diputación Permanente. En efecto, después de cada Cortes extraordinarias sería preciso una disposición normativa singular para establecer en ese supuesto un instrumento de continui-

65 Giraldo. Legislatura 1810-1813. Tomo III. Diario de Sesiones núm. 371, 8 de octubre de 1811, pág. 2016.

${ }^{66}$ En tal sentido AnER. Legislatura 1810-1813. Tomo III. Diario de Sesiones núm. 370, 7 de octubre de 1811, pág. 2012.

${ }^{67}$ Legislatura 1810-1813. Tomo III. Diario de Sesiones núm. 353, 20 de septiembre de 1811.

68 Oliveros. Legislatura 1810-1813. Tomo III. Diario de Sesiones núm. 370, 7 de octubre de 1811, pág. 2011. 
dad, con el riesgo subsiguiente de que tal decisión no fuera tomada, ante lo cual se produciría de hecho y de derecho una discontinuidad cuyos inconvenientes son fácilmente imaginables. Por otra parte, cabe apuntar que esta limitación al intervalo entre Cortes ordinarias chocaba con la redacción del artículo 157 que tomado en su expresión literal establecía un principio general cual es la existencia de una Diputación Permanente nombrada «antes de separarse las Cortes», sin diferenciar si éstas eran ordinarias o extraordinarias.

Esa labor de continuidad o semicontinuidad parlamentaria quedaba manifestada de un modo material en la labor de la Diputación Permanente en cuanto a la disposición del trabajo futuro de las siguientes Cortes. Pudiera parecer ociosa esta precisión por ser algo baladí, poco acorde con el significado que en esencia había que atribuir al órgano de continuidad. Sin embargo, esa apreciación no es del todo correcta puesto que el trabajo parlamentario en la época de que se trata precisaba de un apoyo material y preparación técnica que dado el estado primitivo de nuestro parlamentarismo sólo podría satisfacer, por sí misma o bajo su dirección, la Diputación Permanente y ello desde un doble punto de vista:

- Preparación material: la Diputación Permanente estaría encargada de proporcionar a las Cortes venideras cuantos instrumentos materiales necesitasen para el cumplimiento de su labor. Con ello podría evitarse el desolador panorama que Luján pone de manifiesto al referirse al inicio de las Cortes Constituyentes «en que la única preparación y disposición que encontraron para los grandes trabajos que les esperaban, y para las reformas que emprendían y se les había encargado, fue un tintero y unos pocos cuadernos de papel común» ${ }^{69}$.

- Preparación técnica: la Diputación Permanente se encargaba de la confección de aquellos expedientes y documentación que podían servir a las Cortes para lo cual contaban éstas con un instrumento técnico que servía de base a su trabajo. Tal era el cometido que los Reglamentos le encomendaban al disponer que «la Diputación permanente se ocupará en meditar y extender aquellos informes que sobre cualesquiera materias le hubiesen sido encargados por las Cortes, a fin de presentarlos a éstas en estado de resolución al comenzar las sesiones» (arts. 199 del Reglamento de 1813 y 243 del Reglamento de 1821).

${ }^{69}$ LujAN, ibídem, pág. 2012. 


\subsection{Defensa constitucional}

Sin duda, una de las grandes preocupaciones de los constituyentes gaditanos fue la de establecer mecanismos que garantizasen la observancia de la Constitución aunque el resultado final no fue satisfactorio porque no se diseñó un sistema específico de defensa constitucional sino que esa tarea se encomendaba en general a las propias Cortes y en particular a su Diputación Permanente cuando asumiera sus funciones, entendiéndola por ello «con una finalidad genérica de defensa de la Constitución» ${ }^{70}$. Los constituyentes no asumieron la recomendación de Miguel Agustín Jarillo, cura de Higuera la Real, obispado de Badajoz, quien en su Memoria de 10 de septiembre de 1809, dirigida a las Cortes sobre lo que, a su juicio, debía contener la Constitución, consideraba «oportuna y eficaz la eleción de un tribunal con el nombre de Constitucional cuyo destino y cuya ocupación sea sola y únicamente velar sobre la más exacta observancia de la Constitución y leyes establecidas en las Cortes Generales ${ }^{71}$. Las razones para atribuir ese cometido a la Diputación Permanente eran razones meramente históricas enlazadas con el ejemplo de la institución equivalente de la Edad Media cuando tenía «el carácter de órgano continuador de sus mandatarios las Cortes, con atribuciones excepcionales para velar, en el entretanto, por la observancia de las leyes. Por lo que tenían de garantía contra las posibles violencias del poder real, fueron ahora rememoradas como base inspiradora de un organismo que viniera a realizar finalidad parecida a la de aquellas ilustres diputaciones» ${ }^{72}$. Por ello se consideró que «el medio principal para hacer observar la Constitución es que haya una diputación con autoridad, facultades señaladas, actividad y energía» ${ }^{73}$.

\subsection{Administración parlamentaria}

Los períodos de inactividad alteran la distribución de competencias de los distintos elementos que componen las Cortes. En ausencia de la complejidad actual, el esquema interno de las Cortes durante la vigencia de la Constitución de 1812 era simple. Por ello, durante los intervalos de inactividad, la Diputación

70 Sánchez Agesta, Luis, Historia del Constitucionalismo español, $4^{\mathrm{a}}$ edición revisada y ampliada, Centro de Estudios Constitucionales, Madrid, 1984, pág. 77.

71 Archivo del Congreso de los Diputados. Serie General. Legajo 5, exp. núm. 49, hoja 3.

72 Jiménez de Gregorio, Fernando, «La Convocación de Cortes Constituyentes en 1810. Estudio de la opinión española en punto a la reforma constitucional», en Estudios de Historia Moderna, t. V, art. $4^{\circ}, 1955$, pág. 256.

73 Giraldo. Legislatura 1810-1813. Tomo III. Diario de Sesiones núm. 371, 8 de octubre de 1811, pág. 2016. 
Permanente asumía la dirección de las actividades internas de la Cámara así como las labores ordinarias materiales y de gestión.

\section{FACULTADES DE ACTUACIÓN}

Haciendo referencia a las funciones que constitucional y reglamentariamente se atribuían a la Diputación Permanente es preciso diferenciar las facultades concretas de las que disponía para llevar a cabo su labor.

\subsection{En orden a su función de garantía constitucional}

Según el artículo 160. Primera de la Constitución, era facultad del órgano «velar sobre la observancia de la Constitución y las leyes, para dar cuenta a las próximas Cortes de las infracciones que hayan notado». En efecto, «es la atribución que figura consignada en primer término. Es también la que despierta en el ánimo mayor interés ${ }^{74}$, aunque esa expectativa se vio de algún modo incumplida por el ejercicio concreto que de ella hizo la Diputación Permanente, desprovista además de capacidad de iniciativa en tal supuesto. El Proyecto elaborado por la Comisión limitaba esta facultad a la vigilancia del cumplimiento de la Constitución, siendo el diputado Giraldo quien propusiera la adición de un párrafo que la extendiera a la observancia de «las leyes haciendo las reclamaciones oportunas para ello» ${ }^{75}$. Ello dio lugar a un debate sobre la interpretación del término velar y si procedía incluir constitucionalmente esa posibilidad de reclamación activa respecto a las infracciones observadas en cuanto al cumplimiento de la Constitución.

Respecto al significado y alcance del vocablo velar resultaba un concepto jurídico indeterminado que en Cádiz se entendía de una doble manera, esto es, o había interés de dotar a la Diputación Permanente de posibilidades de actuación efectiva o se la consideraba como un órgano pasivo que veía y apuntaba, en palabras de Espiga «una centinela que observe las infracciones que pueda haber para dar cuenta a las próximas Cortes ${ }^{76}$. Esta visión restrictiva fue rebatida defendiéndose la necesidad de fijar los medios de que había de valerse la Diputación

74 Pérez Serrano, Nicolás, op. cit., pág. 175.

75 Giraldo. Legislatura 1810-1813. Tomo III. Diario de Sesiones núm. 371, 8 de octubre de 1811, pág. 2016.

76 EspigA. Legislatura 1810-1813. Tomo III. Diario de Sesiones núm. 371, 8 de octubre de 1812, pag. 2018. 
Permanente para llevar a cabo esa vigilancia pues de lo contrario dependería de la discrecionalidad de los diputados en cada momento. Además, ello debería plasmarse en el propio texto constitucional y no en el Reglamento interior de Cortes como se propuso por parte de la Comisión, porque los medios que se establecieran tenían carácter constitucional, no reglamentario y no podían ver comprometido su cumplimiento por una posterior reforma ordinaria.

Desechándose el precedente histórico de la Diputación de Navarra que presentaba sus reclamaciones contra disposiciones o actos contrarios a su legislación ante los tribunales como representantes regios, ahora se apostaba por esa presentación ante el Rey o el Consejo de Regencia, en su caso, dado el carácter de Diputación de toda la monarquía y el hecho de tener su sede en la Corte con la posibilidad de recurrir directamente al monarca ${ }^{77}$. Las oportunidades que brindaban esas reclamaciones no convencían a todos los diputados. Unos mantenían una posición de ambigüedad afirmando su disponibilidad a reconocerlas jurídicamente pero negándose luego en la práctica (Argüelles, Muñoz Torrero) y otros fueron tajantes al oponerse a que se reconociera constitucionalmente ese tipo de reclamaciones, siendo la crítica más elaborada la de Cañedo ${ }^{78}$ basada en dos razones, una de forma y otra de fondo. En cuanto a la primera, la reclamación habría de plantearse contra los tribunales o contra el Gobierno. En todo caso habría de saberse ante quién se presentaba. Si era contra el Gobierno resultaba absurdo presentarla ante el mismo y si era contra los tribunales podría servir de pretexto para anular la independencia del poder judicial reconocida en la Constitución. En cuanto al fondo, si se adoptaba la facultad de reclamar y contrafuero al estilo de Navarra, entendía Cañedo que sería fácil a la Diputación «frustrar las providencias del Gobierno y las sentencias de los tribunales».

La consecuencia de esos recelos de los constituyentes fue que aunque se aprobó la primera parte de la adición presentada por Giraldo no se incluyó la posibilidad de que la Diputación Permanente presentase directamente las reclamaciones que considerase oportunas.

Se llega así al extremo central de estas líneas, es decir, fijar con claridad el alcance de la labor de la Diputación Permanente como garante constitucional. Battaglini no duda en afirmar que «el capítulo X de la Constitución de 1812 contiene un instituto que representa una tentativa de control constitucional de la actividad legislativa del parlamento después de que estaba disuelto» ${ }^{79}$. Se apun-

77 ANER, ibídem, pág. 2017.

78 CaÑEDO, ibídem, pág. 2019.

79 Battaglini, Mario, Contributi alla storia del controllo di constituzionalita delle leggi, Giuffré, Milano, 1954, pág. 114. 
tó anteriormente que la función atribuida al órgano de continuidad en el texto gaditano podía entenderse como germen de un futuro sistema de defensa constitucional pero sin que pueda implicar de manera automática que se le reconozca el significado de un Tribunal Constitucional al estilo moderno con competencias para resolver eventuales procesos de constitucionalidad que le fueran planteados. El error de Battaglini radica, por tanto, en confundir el tipo de infracciones de las que debía conocer la Diputación Permanente. No se trataba de violaciones presuntamente cometidas por las Cortes en el ejercicio de su función legislativa, sino de aquellas actuaciones de otros órganos del Estado, de forma destacada el ejecutivo, que supusieran desconocimiento de las previsiones constitucionales y pudieran acarrear vulneración de los derechos de los ciudadanos plasmados en el texto de 1812. Por ello Tomás Villarroya considera «demasiado elemental» ${ }^{80}$ esgrimir ese dato como auténtico antecedente del actual recurso de inconstitucionalidad, cuyo único valor lo encuentra Martín-Retortillo en «la pura erudición histórica» ${ }^{81}$. Aunque deba reconocerse que el texto constitucional no fue generoso en este orden con el significado de la Diputación Permanente tampoco justifica una interpretación crítica de la misma considerando que «no es ninguna instancia garantizadora de la aplicación y eficacia de la Constitución ya que se limita a tramitar las quejas» ${ }^{82}$.

Es cierto el carácter instructorio de su cometido pero también se vio con anterioridad que en momentos difíciles para el orden constitucional el compromiso de los miembros de la Diputación Permanente estuvo muy por encima de la literalidad de la Constitución, convirtiéndose entonces en su garante efectivo. Incluso en situaciones de normalidad hubo muestras de ese afán como cuando acordó «manifestar al Ministerio, por conducto del de Gobernación de la península, que espera de su acreditado celo y patriotismo le comunicará cuantos datos y conocimientos puedan contribuir al mejor desempeño de tan sagrada obligación» ${ }^{83}$. Lo cierto es que la propia Diputación Permanente nunca mostró signos de inconformismo con ese papel subsidiario que le reconocían las normas, tal y como quedó patente desde la primera reclamación por presunta infracción

80 Tomás Villarroya, Joaquín, «El recurso de inconstitucionalidad en el Derecho español (1931-1936)», en Revista del Instituto de Ciencias Sociales, núm. 11, 1960, pág. 12.

81 Martín-Retortillo BaQuer, Sebastián, «Consideraciones sobre los Tribunales Constitucionales», en Revista Española de Derecho Administrativo, núm. 15, octubre-diciembre 1977, pág. 554.

82 Lorente Sariñena, Marta, op. cit., pág. 25.

83 Sesiones de las Cortes. Actas Secretas 1820-1823. Tomo único, sesión del día 13 de septiembre de 1820, pág. 47. Semejante iniciativa fue adoptada en la sesión día 6 de agosto de 1823, ibídem, pág. 689. 
de Constitución, recibida por la Diputación Permanente en su sesión de 23 de septiembre de 1813. Se trataba de una representación de don José María Aurrecoechea y don José Antonio de Zalbidea, síndicos comisarios de la quiebra y concurso de acreedores de la Casa de Torre Hermanos, sobre infracción de Constitución cometida por el Supremo Tribunal de Justicia ${ }^{84}$. Ya en aquella ocasión se tomó el acuerdo de que el expediente y su extracto se guardase para presentarlo a las Cortes. Ese era, por lo demás, el sentido de los Reglamentos de 1813 y 1821 que mandaban que la Diputación Permanente recibiera las quejas de infracción de Constitución y por medio de la Secretaría formase extractos clasificados de ellas, reservándolas para dar cuenta a las Cortes (arts. 189 y 228, respectivamente).

Hay que resaltar que la instrucción de ese tipo de expedientes no era el único medio que tenía la Diputación Permanente para dar cumplimiento a la Constitución. En situaciones delicadas, y por su propia voluntad, podía adoptar iniciativas de distinta naturaleza según el caso. Así, por ejemplo, el oficio enviado al Secretario del Despacho de la Guerra en 1823:

«Excmo. Sr.: Encargada la Diputación Permanente de las Cortes de velar sobre la observancia de la Constitución, no puede dejar de considerar que faltaría esta observancia y aun la Constitución misma, si la Isla Gaditana, residencia actual de la Real Familia, del Gobierno y de la Representación Nacional, cayese en manos de nuestros enemigos. Bajo este punto de vista, la seguridad de la isla está identificada hasta cierto punto con la subsistencia del régimen constitucional, y debe ser por ello objeto más o menos directo de la vigilancia de la Diputación. Voces esparcidas con bastante generalidad entre personas de todas clases, y que se extiende aun en los periódicos, anuncian que no está hecho todo lo necesario para la defensa, y que no se hace todo lo posible, o al menos no se hace con la celeridad activa que exigen las circunstancias y que permiten las facultades extraordinarias concedidas al Gobierno, y las que competen a los jefes militares de las plazas y puntos sitiados. La Diputación no puede calificar el fundamento de aquellas voces, ni fijar, en la hipótesis de que lo tengan, si la falta está en el Gobierno o en las manos ejecutoras, de que necesariamente tiene que valerse; pero siendo indudable que en aquella hipótesis peligran la Constitución y su observancia, y debe haber infracción de las leyes y decretos que regulan la conducta de los empleados públicos, está la Diputación en el caso de tomar los conocimientos necesarios para dar cuenta a las Cortes, con arreglo a lo dispuesto en el art. 160 de la Constitución, si se hallaren méritos suficientes, a cuyo fin

84 Actas Secretas de 1810-1814. Tomo único, sesión del día 23 de septiembre de 1813, pág. 885. El número de quejas recibidas por la Diputación Permanente fue: $1^{\mathrm{a}} \mathrm{DP}$ : sólo la reseñada; $2^{\mathrm{a}}$ DP: dos quejas; $3^{\mathrm{a}}$ DP: 54 quejas; $4^{\mathrm{a}} \mathrm{DP}$ : 28 quejas; $5^{\mathrm{a}} \mathrm{DP}: 108$ quejas; y $6^{\mathrm{a}} \mathrm{DP}$ : ninguna queja. 
ha considerado dirigirse al Gobierno Lo comunico a V. E., de acuerdo de la misma Diputación ${ }^{85}$.»

o el enviado al Gobierno por conducto del Secretario de la Gobernación de la Península para informarse, puesto que si bien «no está en las atribuciones de la Diputación ni el tomar medidas que no estén en sus atribuciones, ni mezclarse en providencias gubernativas... sí lo está, como guarda de la Constitución y de las leyes, el pedir las noticias convenientes sobre las infracciones de una y de otras que puedan haberse cometido, confiando en el celo del Gobierno, que desplegará toda su energía en materia de tanta gravedad, para que no se repitan sucesos tan desagradables» ${ }^{86}$.

\subsection{En orden a su función de continuidad}

Siguiendo el articulado constitucional, cabe distinguir entre facultades relativas a una función de continuidad constitucional y facultades relativas a una función de continuidad parlamentaria material.

\subsubsection{Facultades en orden a su función de continuidad constitucional}

Según el artículo 160. Segunda de la Constitución, era facultad de la Diputación Permanente «convocar a Cortes extraordinarias en los casos prescritos por la Constitución». Estos eran los que se enumeraban en el artículo 162:

Primero. Cuando vacare la Corona. Esta facultad implicaba la necesidad de probar el fallecimiento del monarca exigiéndose por vía reglamentaria para caso de hallarse el Rey enfermo y agravarse su estado, aviso por el Secretario de Gracia y Justicia a la Diputación Permanente, dos de cuyos integrantes asistirían alternando todos los días y en cada hora a la antecámara del Rey hasta que éste saliese de peligro o falleciese, en cuyo caso, los dos miembros de la Diputación Permanente debían entrar en la cámara real cerciorándose del fallecimiento, extendiéndose a continuación testimonio del fallecimiento por el Secretario de Gracia y Justicia que habría de ser firmado por los diputados y refrendado y legalizado por dicho Secretario por duplicado, sirviendo un ejemplar para que se

85 Actas Secretas de 1820-1823. Tomo único, sesión del día 4 de septiembre de 1823, pág. 714. Asimismo cabe citar la exposición enviada al Rey con motivo del nombramiento como Ministro de la Guerra del general D. Gregorio Rodríguez, el 4 de septiembre de 1821, ibídem, págs. 253 y 254.

86 Ibídem, pág. 258. 
lea en la Diputación Permanente, custodiándolo en el archivo para dar cuenta de él en las próximas Cortes (cfr. arts 192 y 193 del Reglamento de 1813 que coinciden con los arts. 236 y 237 del Reglamento de 1821).

Segundo. Cuando el Rey se imposibilitare de cualquier modo para el gobierno, o quisiere abdicar la corona en su sucesor; estando autorizada la diputación para tomar todas las medidas que estime convenientes, a fin de asegurarse de la inbabilidad del Rey. El primer inciso del párrafo establecía una facultad obligatoria en cuanto a su ejercicio pero potestativa respecto a la valoración de las circunstancias previas que la legitiman, por lo que planteaba el problema inicial de saber quién debía ser el encargado de declarar la imposibilidad regia y un problema adicional, determinar los medios y criterios para constatar fehacientemente esa imposibilidad al objeto de eliminar cualquier atisbo de discrecionalidad que supusiera una intromisión ilegítima de la Diputación Permanente en la actuación del Rey. Y aun suscitaba un tercer interrogante respecto al alcance exacto de la expresión «se imposibilitare de cualquier modo para el gobierno» que podía entenderse referida tanto a una imposibilidad física como mental. De los debates constituyentes se deduce que se pensaba sólo en la imposibilidad física pero al hablar de «cualquier modo» se podía defender una separación del monarca basada en razones jurídicas e incluso políticas ante la eventual violación reiterada por su parte de la Constitución, algo que se llegó a plantear como hemos visto al referirnos a la naturaleza del órgano de continuidad.

En cuanto al sujeto competente para declarar la imposibilidad del Rey, el silencio constitucional se suple por el principio reglamentario de que sea la Diputación quien, después de cerciorarse de la imposibilidad regia, convocare las Cortes extraordinarias (arts. 195 del Reglamento de 1813 y 239 del Reglamento de 1821) puesto que éstas se limitaban, en virtud de los citados preceptos reglamentarios, a que «declaren lo que se previene en el artículo 187 de la misma — de la Constitución—», es decir, nombrar la Regencia que había de gobernar el reino «cuando el Rey se halle imposibilitado de ejercer su autoridad por cualquier causa física o moral», siendo en consecuencia su actuación a posteriori, determinando los efectos de una situación que ha debido ser calificada a priori por la Diputación Permanente.

Por lo que se refiere a los medios para determinar la imposibilidad, se debería haber adoptado constitucionalmente una serie de instrumentos que garantizasen el rigor de los diputados. El texto definitivo del precepto constitucional tuvo su origen en una adición propuesta por García Herreros que se admitió a discusión y se mandó pasar a petición de Argüelles a la Comisión para que se arreglase en los términos más convenientes. La adición proponía «la notoriedad o una declaración jurada de hallarse el Rey en ese estado, dada por 
los médicos que le asistan es bastante para que por esta causa se haga la convocatoria» ${ }^{87}$. En la sesión de 1 de noviembre de 1811 se aprobó el dictamen de la Comisión sobre varias propuestas, incluida la de García Herreros. La Comisión sostuvo que estos pormenores no eran propios del contenido de una Constitución sino de Reglamentos o leyes particulares, más sujetos a variaciones que pueda exigir la experiencia y que si debía decir algo, podría añadirse en el párrafo segundo del artículo 162 lo siguiente: «estando autorizada en el primer caso — cuando el Rey se imposibilitare — la Diputación para tomar todas las medidas que estime convenientes a fin de asegurarse de la inhabilidad del Rey» ${ }^{88}$. Esa genérica libertad de la Diputación Permanente quedó de alguna manera restringida por los artículos 195 y 239 de los Reglamentos de 1813 y 1821 respectivamente, puesto que «para asegurar la Diputación permanente de si ha llegado o no el caso de convocar a Cortes extraordinarias por la razón de la inhabilidad del Rey para el gobierno por causa física o moral, oirá el dictamen de una junta de médicos de cámara y de los demás facultativos que estime conveniente; y si la causa fuere moral, oirá asimismo el dictamen del Consejo de Estado...».

Tercero. Cuando en circunstancias críticas y por negocios arduos tuviere el Rey por conveniente que se congreguen, y así lo participare a la Diputación permanente de Cortes. La palabra críticas sustituyó al término inicial de difíciles a propuesta del Conde Toreno. Pese a la indeterminación tanto de los motivos que debían de motivar la convocatoria como del objeto de la misma, debe resaltarse el significado del párrafo, el respeto a la voluntad general representado por la Diputación Permanente aunque debiera habérsele reconocido poderes para calificar los motivos de la convocatoria y no tener que estar, en consecuencia, obligada automáticamente a la misma. Desde luego la convocatoria había de hacerla la Diputación Permanente y no el Rey teniendo por ello la actuación del órgano de continuidad el carácter de acto debido al que no podía oponerse por la propia literalidad del inicio del artículo 162 de la Constitución («la Diputación permanente las convocará...»). El modo de hacerlo era mediante una circular firmada por todos sus miembros, expresando el objeto de la convocatoria, pasándola al Gobierno, para que el Secretario de la Gobernación la dirigiera a todos los diputados por medio de los Jefes políticos de las provincias de su residencia, insertándose también este aviso en la Gaceta del Gobierno (arts. 190 del Reglamento de 1813 y 229 del

87 García Herreros. Legislatura 1810-1813. Tomo III. Diario de Sesiones núm. 372, 9 de octubre de 1811, pág. 2024.

88 Legislatura 1810-1813. Tomo III. Diario de Sesiones núm. 395, 1 de noviembre de 1811, pág. 2195. 
Reglamento de 1821). En esos mismos artículos se aludía a la posibilidad de que el Reino estuviese gobernado por una Regencia, en cuyo caso correspondía a la misma pedir a la Diputación Permanente la convocatoria de Cortes extraordinarias por las circunstancias señaladas en el artículo 162. Tercero de la Constitución ${ }^{89}$.

La solicitud de convocatoria a petición de la Regencia sólo tuvo lugar en la sesión octava de la Diputación Permanente, el día 16 de septiembre de 1813 cuando «a las nueve y diez minutos de la noche se recibió un oficio del Gobierno, en que, por medio del Secretario de Gobernación, pedía la Regencia se convocasen las Cortes extraordinarias al momento, y que se circulase la correspondiente convocatoria a los Sres. Diputados existentes en la plaza» ${ }^{90}$.

\subsubsection{Facultades en orden a su función de continuidad parlamentaria material}

La tercera facultad que el artículo 160 de la Constitución reconocía a la Diputación Permanente era la de «desempeñar las funciones que se señalan en los artículos 111 y 112». El primero se refería a la presentación obligatoria de los diputados según fueran llegando a la capital ante la Diputación Permanente para que ésta sentase sus nombres y el de la provincia que les hubiera elegido, en un registro en la secretaría de las mismas Cortes. El artículo 112 atribuía a la Diputación Permanente el carácter de Mesa provisional ya que la primera junta preparatoria en el año de la renovación de los diputados sería presidida por el Presidente de la propia Diputación Permanente y haciendo de secretarios y escrutadores los que haya nombrado la propia Diputación entre sus demás componentes, para lo cual «la Diputación permanente tendrá dadas todas las providencias necesarias para que la primera junta preparatoria se verifique en el día señalado por la Constitución» (arts. 11 de los Reglamentos de 1813 y 1821), es decir, el 15 de febrero, abriendo la sesión el Presidente de la Diputación «por un breve discurso correspondiente a las circunstancias» (arts. 13 de los Reglamentos de 1813 y 1821). La Diputación Permanente presidía también las siguientes jun-

${ }^{89}$ Las convocatorias de Cortes extraordinarias por estos motivos fueron:

1. En la sesión de 13 de agosto de 1821 se convocaron Cortes extraordinarias para el 28 de septiembre. Actas Secretas 1820-1823, pág. 233.

2. En la sesión de 6 de septiembre de 1822 se convocaron Cortes extraordinarias para el 7 de octubre, ibídem, pág. 513.

3. En la sesión extraordinaria de la noche del 5 de septiembre de 1823 se convocaron Cortes extraordinarias para el día siguiente, ibídem, pág. 716.

90 Actas Secretas de 1810-1814. Tomo único, pág. 878. 
tas preparatorias hasta la última que había de celebrarse según el artículo 17 de la Constitución el día 25 de febrero.

Por otra parte, el mismo artículo 160 de la Constitución establecía como cuarta facultad de la Diputación Permanente «pasar aviso a los diputados suplentes para que concurran en lugar de los propietarios; y si ocurriese el fallecimiento o imposibilidad absoluta de propietarios y suplentes de una provincia, comunicar las correspondientes órdenes a la misma, para que proceda a una nueva elección». El artículo, tal y como procedía de la Comisión, fue cuestionado por algunos constituyentes en cuanto a su última parte por los inconvenientes que presentaba la realización de nuevas elecciones y la dificultad material que ello supondría en relación con las provincias de Ultramar.

Por lo demás, correspondía a la Diputación Permanente la preparación del trabajo parlamentario de las futuras Cortes para lo cual «recibirá todas las Memorias y proyectos que se le remitan, y los examinará para presentarlas a las Cortes con el orden y método que lo hacen las Comisiones, si le pareciere que merecen su consideración» (arts. 200 del Reglamento de 1813 y 244 del Reglamento de 1821), en cuyo cumplimiento «en el día siguiente al de la solemnidad de la apertura de las sesiones se leerá el acta de la Junta preparatoria de 25 de febrero y la lista de las Comisiones que se hayan nombrado. En seguida se dará cuenta del extracto de los trabajos preparados por la Diputación permanente, para que pasen a las Comisiones respectivas» (arts. 76 del Reglamento de 1813 y 81 del Reglamento de 1821).

La Diputación Permanente continuaba en las funciones señaladas en los artículos 111 y 112 en el supuesto de que las Cortes extraordinarias no concluyesen sus sesiones en el día señalado para las ordinarias que en tal caso continuarían el objeto para el que aquellas fueron convocadas (art. 167 de la Constitución en relación con el artículo 166 de la misma).

\subsubsection{Facultades en orden a su función de administración parlamentaria}

Los Reglamentos parlamentarios, como se indicó con anterioridad, ponían a cargo de la Diputación Permanente el orden y gobierno interior del edificio de las Cortes y bajo sus órdenes las oficinas y subalternos, con la limitación de no poder despojar de su cargo a ningún funcionario sino tan sólo con la posibilidad de suspenderlos con justa causa dando después cuenta a las Cortes. La Diputación Permanente también tenía competencia para ordenar cualquier obra o reparación que fuera necesario hacer con urgencia en el edificio de las Cortes, asimismo con la obligación de dar cuenta a posteriori (arts. 186 del Reglamento de 1813 y 220 del Reglamento de 1823). 
Es precisamente esta faceta la que el propio órgano de continuidad llega a considerar más gravosa. Así, en la exposición remitida a las Cortes el 25 de febrero de 1822 dando cuenta de su labor, entiende que «no ha sido el de los muchos expedientes, el cuidado que más ha molestado la atención de la Diputación: encargada del Gobierno interior del edificio y de todo el régimen económico de las mismas, ha tenido que atender incesantemente a tan incómodo y prolijo trabajo ${ }^{91}$. Las obras o reparaciones a efectuar en el edificio de las Cortes también eran del conocimiento de la Diputación Permanente acordando en consecuencia «que ninguna se haga en adelante sin previo conocimiento y resolución de la misma, o en su caso de la Comisión de Gobierno interior de las Cortes; y que no se abonen por la Contaduría las cuentas que carezcan de este requisito, a las cuales deberá acompañar el visto bueno del inspector arquitecto de las mismas, en las obras que fueran de su atribución» ${ }^{92}$. El asunto de estas obras y reparaciones llega a ocupar largamente a la Diputación Permanente hasta el punto de que alguna sesión casi se ocupa en exclusiva de tales cuestiones ${ }^{93}$.

\section{CONCLUSIONES}

El reconocimiento de un órgano de continuidad parlamentaria en la Constitución de 1812 constituyó un hecho destacado porque buscaba el propósito de eliminar cualquier injerencia regia en el funcionamiento del poder legislativo. Sin embargo, la Constitución desaprovechó esta posibilidad creando una figura pobre en atribuciones específicas, con una inconcreción funcional incompatible con el alto significado que teóricamente quería atribuirle. Sus funciones no se corresponden con las facultades que se recogen constitucional y reglamentariamente, quedando aquellas reducidas, en los supuestos más característicos, a vagos principios o ideas programáticas sin un correlativo práctico eficaz. Destaca la misión encomendada como garante del propio texto constitucional pero reconociendo a la Diputación Permanente un papel subsidiario, de paso intermedio hasta las Cortes que en definitiva son las que resuelven. En consecuencia, y a modo de resumen, puede sostenerse que la Diputación Permanente en la Constitución de Cádiz fue la gran ocasión perdida de construir un auténtico control del cumplimiento del texto constitucional.

91 Actas Secretas 1820-1823. Tomo único. Sesión de 25 de febrero de 1822, pág. 408.

92 Ibídem, sesión de 6 de diciembre de 1820, pág. 81.

93 V. gr. Sesiones de 13 y 29 de noviembre; y 6, 9 y 13 de diciembre de 1820. 
Title:

THE PERMANENT DELEGATION IN THE CONSTITUTION OF CÁDIZ or the FRUSTRATED ATTEMPT TO CREATE AN ORGAN WITH FUNCTIONS OF CONSTITUTIONAL GUARANTEE

\section{Resumen:}

La Diputación Permanente de la Constitución de 1812 es el órgano de continuidad parlamentaria para mantener la representación de la voluntad popular en los períodos en los que las Cortes no estuvieran trabajando en plenitud. Significó también un intento frustrado de establecer un mecanismo eficaz para garantizar el cumplimiento del propio texto constitucional y por tanto su defensa ante las violaciones por parte de otros órganos del Estado.

\section{Summary:}

1. Introduction. 2. Denomination. 3. Constitucionalización of the organ. its justification. 4. Dual characterization of nature. A) Legal nature. B) Political nature. 5. Characteristics. A) Historical character. B) Progressive sense. C) Spirit of control. 6. Its assignment. Constitutional functions. 6.1 Parliamentary continuity. 6.2. Constitutional defense. 6.3. Parliamentary administration. 7. Performance faculties. 7.1. In sequence to its function of constitutional guarantee. 7.2. In sequence to its function of continuity. 7.2.1. Faculties in sequence to its function of constitutional continuity. 7.2.2. Faculties in sequence to its function of material parliamentary continuity. 7.2.3. Faculties in sequence to its function of parliamentary administration. 8. Conclusions.

\section{Abstract:}

The Permanent Delegation of the Constitution of 1812 is the parliamentary body to maintain continuity of the representation of popular will in the periods in which the courts were not working fully. It also meant an unsuccessful attempt to establish an effective mechanism to ensure compliance with the constitutional text itself and therefore its defense against violations by other state bodies.

Palabras clave:

Constitución, Parlamento, continuidad parlamentaria, defensa de la Constitución, infracciones, representación.

Key words:

Constitution, Parliament, parliamentary continuity, defense of the Constitution, violations, representation. 